\title{
Queuing Theory and ATM Service Optimization: Empirical Evidence from First Bank PIc, Kaura Namoda Branch, Zamfara State
}

\author{
Muhammad Sani Burodo, ${ }^{1,}$, Shamsuddeen Suleiman², Yakubu Shaba ${ }^{3}$ \\ ${ }^{1}$ Department of Business Administration and Management, Federal Polytechnic, Kaura Namoda, Nigeria \\ ${ }^{2}$ Department of Mathematics, Faculty of Science, Usmanu Danfodiyo University, Sokoto, Nigeria \\ ${ }^{3}$ Department of Business Administration, Faculty of Management Sciences, Usmanu Danfodiyo University, Sokoto, Nigeria \\ Email address: \\ muhammadsaniburodo@gmail.com (M. S. Burodo), Suleman.shamsuddeen@udusok.edu.ng(S. Suleiman), \\ yakubushaba@gmail.com (Y. Shaba) \\ ${ }^{*}$ Corresponding author
}

\section{To cite this article:}

Muhammad Sani Burodo, Shamsuddeen Suleiman, Yakubu Shaba. Queuing Theory and ATM Service Optimization: Empirical Evidence from First Bank Plc, Kaura Namoda Branch, Zamfara State. American Journal of Operations Management and Information Systems. Vol. 4, No. 3, 2019, pp. 80-86. doi: 10.11648/j.ajomis.20190403.12

Received: June 27, 2019; Accepted: August 16, 2019; Published: September 5, 2019

\begin{abstract}
The consequence of queuing in relation to the time spent by customers to access financial services is increasingly becoming a major source of concern to most stakeholders, especially the banks, their teeming customers and regulatory agencies. Even more critical are the costs that accrue thereof. In this study, the queuing characteristics at the Kaura Namoda Branch of First Bank Ltd were analyzed using three service efficiency parameters - single, two and three servers. The study collected, through observation, queuing data at the bank from Monday through Wednesday to develop an optimal queuing model. Consistent with conventional wisdom and prior studies, the findings provide evidence to support the idea that the multiple-server model is more efficient than the single channel. For instance, whilst with two or three servers, a customer spends on the average, 0.0409 hours (about 3 minutes) and 0.0310 hours (about 2 minutes), the same customer spends an average of 0.2 hours (12 minutes) in the system if it is a single channel. Thus, the study concludes that higher number of servers is associated with lower average time spent in the system, a finding that is in tandem with past studies within and outside Nigeria. Drawing from these findings, the study suggests the need to increase number of servers to meet the changing expectations of the bank's teeming customers.
\end{abstract}

Keywords: Queuing Theory, Arrival Rate, Service Rate, Server, Customers

\section{Introduction}

The demand for service efficiency has never been on the decrease. This phenomenon is even more critical in the banking subsector. Undoubtedly, queuing theory has been practically a successful tool in the analysis of waiting lines [1]. The objective is to have an optimal model that is capable of improving the queuing system - a method that can optimize the number of servers, improve service efficiency that is capable of minimizing service cost and customers' waiting time and thus enhance firm performance.

In a bid to improve efficiency in the Nigerian banking system, Automated Teller Machines (ATMs) were introduced in early 2000. However, prior to the introduction, the Nigerian banking system was characterized by frustrations and poor services occasioned by ineffectiveness and inefficiency in the services delivered. Customers were made to endure overcrowded and congested banking halls, long hours of queue before being served and rude and overworked bank staff who sometimes vent their frustrations on the customers. Without doubt, the introduction of ATMs has significantly impacted the banking system in many ways. For instance, it has drastically reduced these undesirable experiences and brought banking services closer to the people as it is not uncommon to find ATMs in places where ordinarily banks are not located. Apart from enhancing 
service delivery, this effort has also provided a lot of reliefs for banks from the pressure of overcrowded banking halls and long queues of customers waiting to be served at teller points. It is in line with this that it is argued that the benefits of the facility to the banking system include but not limited to investment opportunities, reduction in costs, satisfaction of customers and competitiveness [2]. Similarly, it provides evidence to prove that ATM facilities increase transaction speed and thus save customers' time [3].

However, the introduction of the facility to the banking system was not without its challenges. Prime among them at the initial stage was ATM fraud. Fraudsters were having a field day cloning ATM cards to defraud unsuspecting customers of thousands and sometimes millions of Naira. These activities were not without insider information in some cases. Consequently, confidence in the facility declined and people were weary of using the facility. Worried by this menace, the Central Bank of Nigeria $(\mathrm{CBN})$ enacted policies that curbed, to a large extent, the wave of the fraud such that the players were made liable for any fraud arising from card skimming and counterfeiting while card holders were made liable in cases of PIN misuse [4]. This regulation forced Nigerian deposit money banks (DMBs) to confront the challenges making it difficult for fraudsters to clone ATM cards thus minimizing its occurrence.

Queuing situations arise in all aspects of work and life and are typified by the process of queuing for services, i.e., a set of physical units (people or things) which wait in a queue or queues subject to certain rules of behavior before some services are performed on or for each unit in the queue one after the other. It is prevalent in transport systems (e.g., traffic light, toll gates, landing of planes in busy airports), commercial services (e.g., banks, petrol stations, supermarkets, barbering shops), social services (e.g., telephone booths, hospitals, judicial system, legislative arm of government) and business/industrial systems (e.g., typing pool, maintenance shops, airplanes lined up on a runway waiting for permission to take off) among others. The four basic components of a queuing process are customers' arrival, the actual waiting line, service facilities and departure.

The theory of waiting lines is one of the oldest and most widely used quantitative analysis techniques [5-6]. Simply put, it is the study of queue or waiting lines. Understanding the theory and its concept is basic to service situations. It optimizes the number of service facilities and adjusts the times of services [7]. This is because a large proportion of both capital and labour is tied up in service facilities; there is therefore clearly a large potential area of application of the theory and huge savings to be obtained. Some of the analysis that can be derived using queuing theory include the expected waiting time in the queue, the average time in the system, the expected queue length as well as the probability of the system to be in certain states, such as empty or full.

The theory gives a basis for understanding the various aspects of the queuing problems and enables a quantitative assessment to be made, hence, enabling service situations to be effectively designed and operated. In order to contribute to the ongoing debate, this paper uses queuing theory to study the waiting lines in First Bank Ltd, Kaura Namoda Branch, Zamfara State, Nigeria. To achieve this objective, the study is structured into five sections including this introduction; section two reviews empirical literature while section three details the techniques of analysis. Section four analyzes the results and the last section concludes and details possible policy implications.

\section{Literature Review}

This section reviews past scholarly empirical studies on the application of queuing theory within and outside Nigeria. The review which is limited to African countries is also restricted to commercial banks. This is to enable comparisons as most of the case studies are similar in a number of ramifications.

In an attempt to provide optimal solution to the queuing problems of the Nigerian banking sector, a queuing model aimed at striking a balance between satisfactory service delivery and minimizing the cost thereof was developed [8]. Using descriptive research method, the author collects, through observation, interview and administration of questionnaire, waiting line data at the bank. The study employs arrival and service rates as waiting line variables and multi-channel queuing model as technique of estimation. In line with the customer satisfaction and cost minimization hypothesis, the study posits on the need to adopt a threeserver against a 2 or a 4 -server system. As a consequence, the author suggests that the bank should adopt a three-server model.

Examination of waiting lines and service efficiency of the Indian banking system [1]. In order to optimize the number of servers and improve service efficiency that could effectively cut down service costs and customer's waiting time, the authors proposed an optimized model incorporating the costs of service and waiting time based on queuing theory. The authors find evidence to argue that increase in service level is significantly associated with increases in service efficiency and customer satisfaction which in-turn minimizes customers' waiting time and total system cost. The authors emphasize on the need for Indian commercial banks to try their model because of its feasibility.

Using multiple servers, single queue model (M/M/S) derived from the Markovian Birth-Death Processes, queuing data from a Nigerian deposit money bank were collected to determine the average time customers spend waiting, actual service time, time wasted and cost associated with it [9]. The findings reveal an average arrival and service rates of 0.1207 and 0.156 respectively with the probability that the servers are idle computed at 0.44 . The implication of this probability value is that there are 44 and 56 per cents chances that the servers will be idle and busy respectively. With average numbers of customers in the queue and system standing at 0.1361 and 0.9098 respectively, the average waiting time in the queue is 1.276 and the expected total time lost waiting in 
a day is 3.2664 hours. The study concludes that with three servers, the average waiting time and cost are minimized.

In an attempt to find the optimal number of tellers required for efficient service delivery for Ghana Commercial Bank Ltd, Kumasi Main Branch, queuing characteristics data through observations and interviews for one month were collected [10]. The study, which also administered questionnaire to complement the aforementioned data collection methods, uses multi-server single line queuing model to resolve the conflict between minimizing the costs of waiting and service on one hand and the provision of satisfactory service on the other. The study documents evidence to argue for a five-teller against a four or a six-teller system for it minimizes the average waiting time and total economic cost and increases customer satisfaction. Thus, the study suggests the adoption of the five teller model.

A comparative study to measure customers' arrival and service rates of Wema Bank Plc and Skye Bank Plc all in Owo Local Government Area of Ondo state was conducted. The study which collects data at the two banks simultaneously for three days, analyzed same independently. Comparing the results of the analyses, while Skye Bank Plc recorded a service time value of $0.000022 \%$, that of Wema Bank Plc was computed at $0.019 \%$. Accordingly, the managerial implication of these findings is that Wema Bank Plc may have a negative significant effect on customers as the waiting time is higher compared to its competitor that may experience little or no queues. The results further indicate that increase in number of servers significantly reduces waiting lines positing on the need to increase number of servers as and when appropriate. [11]

Akin to the study carried out [11-12]; a comparative study of Commercial Bank of Ethiopia and Dashen Bank all in Wolaita zone. Data for arrival and service rates of the two banks were simultaneously collected for two days through observation. In Commercial Bank of Ethiopia, Tona branch, customers arrival and service rates were such that on average, 10.2 and 8.6 customers arrive and get served per hour with average waiting time in queue and in system computed at 0.0001 minutes and 0.43 minutes, respectively. Dashen Bank on the other hand, had on average, 7.125 and 6.125 customers' arrival and service rates per hour with average waiting time in queue and system standing at 0.216 minutes and 0.828 minutes, respectively. The findings provide evidence to prove that Dashen Bank has higher waiting and service times than its counterpart. Accordingly, the implication of these findings is that Commercial Bank of Ethiopia is more effective in rendering financial services than Dashen Bank. Their findings also suggest the need to increase the number of servers since doing so will reduce waiting lines in both the queue and the system.

Analyzing the queuing characteristics at the XYZ bank using a multi-server queuing model, waiting and service costs with a view to determining the optimal service level was established. The results show that optimal server level is achieved when both the tellers handle deposits as well as withdrawals with a minimum per hour total cost of Rs. 1,307 against the current Rs. 1,575. The results further show that service cost increases with increase in level of service which in-turn reduces waiting time. To achieve an optimal queuing system, therefore, the authors suggest expanding the service facilities or using models that consider cost optimization. [13]

In a more recent study, modeled and analyzed the queuing characteristics of Banque Commercial edu CongoBCDC/Mbujimayi [10] and [14]. Collecting data at the BCDC for one week through observation, the study employs a Multi-Server Single Line Queuing Model to test its hypotheses. Contrary to the findings of the Ghanaian scholars, the study finds empirical evidence to argue for a six-teller system for the banking system in the Democratic Republic of Congo against a five-teller system that is more suitable for Ghana.

\section{Methodology}

\subsection{Data Collection and Validation}

The study uses primary data collected through observation during working hours from Monday through Wednesday. The inter-arrival times were found to follow Poisson distribution and the service times followed exponential distribution.

\subsection{Techniques of Data Analysis}

There are two major methods of solving a queuing problem namely; mathematical and simulation. This research uses the former which obtains approximated time distributions for arrival and service. Since there is more than one ATM in the banking premises, the study uses queuing models of both single and multiple servers, the model for the system could be represented as $\mathrm{m} / \mathrm{m} / 1$ (single server model) [15-16]: FCFS $a$ ? ? / $a$ ? ? or $\mathrm{m} / \mathrm{m} / \mathrm{s}$ (multi-server model): FCFS $a$ ? ?/a? ?. The following parameters were analyzed for the models.

\subsubsection{Single Server Model $(\mathrm{m} / \mathrm{m} / 1)$ \\ Utilization factor,}

$$
P=\frac{\lambda}{\mu}
$$

Probability of zero customers in the system,

$$
P_{0}=1-P
$$

Probability of having n number of customers in the system when

$$
n>S, P_{n}=\frac{1}{S ! S^{n-s}}\left(\frac{\lambda}{\mu}\right) P_{0}
$$

When

$$
n \leq S, P_{n}=\frac{1}{n}\left(\frac{\lambda}{\mu}\right) P_{0}
$$

Average number of customers in the system, 


$$
L_{s}=\frac{\lambda}{\mu-\lambda}
$$

Average number of customers in the queue,

$$
L_{q}=L_{s}-\frac{\lambda}{\mu}
$$

Average time spent in the system,

$$
W_{s}=\frac{1}{\mu-\lambda}
$$

Average time spent in the queue,

$$
W_{q}=\frac{P}{\mu-\lambda}
$$

Where, $\lambda$ and $\mu$ represent mean customer arrival and service rates respectively, $\mathrm{n}$ signifies number of observations (customers) and $\mathrm{S}$ is a sample space.

\subsubsection{Multi-Server Model $(\mathrm{m} / \mathrm{m} / \mathrm{s})$}

Utilization factor,

$$
P=\frac{\lambda}{s \mu}
$$

Probability of zero customers in the system,

$$
P_{0}=\frac{1}{\left[\sum_{n=0}^{s-1} \frac{(\lambda / \mu)^{n}}{n !}+\frac{(\lambda / \mu)^{s}}{s !} \cdot \frac{1}{1-\lambda /(s \mu)}\right]}
$$

Probability of having $\mathrm{n}$ customers,

$$
P_{n}=(1-P) P^{n}
$$

Average number of customers in the system,

$$
L_{s}=L_{q}+\frac{\lambda}{\mu}
$$

Average number of customers in the queue,

$$
L_{q}=\frac{P_{0}(\lambda / \mu)^{s} P}{s !(1-p)^{2}}
$$

Average time spent in the system,

$$
W_{s}=W_{q}+\frac{1}{\mu}
$$

Average time spent in the queue,

$$
W_{q}=\frac{L_{q}}{\lambda}
$$

Where $\lambda, \mu, n$ and $S$ are as defined earlier and! is factorial Moreover, the parameters of the models were analyzed for three days (Monday to Wednesday) and comparisons were made amongst them. Finally, the efficiency levels of the different models were also compared.

\subsubsection{Assumptions of the Models}

Certain assumptions that were made during the research are:

i. Queue discipline was assumed to be first-come-firstserved (FCFS).

ii. Since infinite number of customers was allowed in the system and the population source taken as such, the study did not take reneging, balking and jockeying of customers into consideration.

\section{Data Presentation and Analysis}

\subsection{Analysis of the Parameters of the Queuing Model for the Monday Congestion}

Number of servers $=2$

Mean customers arrival rate, $\lambda=23$ per hour.

Mean service rate, $\mu=29$ per hour

Hence, utilization factor, $P=\frac{\lambda}{\mu}=\frac{23}{2 * 29}=0.3966$

Probability of having zero customers in the system

$$
P_{0}=\frac{1}{\left[\sum_{n=0}^{s-1} \frac{(\lambda / \mu)^{n}}{n !}+\frac{(\lambda / \mu)^{s}}{s !} \cdot \frac{1}{1-\lambda /(s \mu)}\right]}
$$

$$
\begin{gathered}
P_{0}=\frac{1}{\left[\frac{(23 / 29)^{0}}{0 !}+\frac{(23 / 29)^{1}}{1 !}+\frac{(23 / 29)^{2}}{2 !} * \frac{1}{\left.1-\frac{23}{(2 * 29)}\right]}\right.} \\
\therefore P_{0}=0.4321
\end{gathered}
$$

Average number of customers in the system,

$$
L_{s}=L_{q}+\frac{\lambda}{\mu}=0.9411
$$

Average number of students in the queue

$$
L_{q}=\frac{P_{0}(\lambda / \mu)^{s} P}{s !(1-p)^{2}}=\frac{0.4321\left(\frac{23}{29}\right)^{2}(0.3966)}{2 !(1-0.3966)^{2}}=0.1480
$$

Average time spent in the queue, $W_{q}=\frac{L_{q}}{\lambda}=\frac{0.1480}{23}=$ 0.0064

Average time spent in the system, $W_{s}=W_{q}+\frac{1}{\lambda}=$ $0.0064+\frac{1}{29}=0.0409$

The probability of having $\mathrm{n}$ customers in the system

$$
\begin{gathered}
P_{n}=\frac{1}{S ! S^{n-s}}\left(\frac{\lambda}{\mu}\right) P_{0} \text { when } \mathrm{n}>\mathrm{S} \\
P_{n}=\frac{1}{n}\left(\frac{\lambda}{\mu}\right) P_{0} \text { when } n \leq S
\end{gathered}
$$

Since when $n=0, P_{0}=0.4321$

When $n=1=\frac{1}{1}\left(\frac{23}{29}\right) 0.4321=0.3427$

When $n=2=\frac{1}{2}\left(\frac{23}{29}\right) 0.4321=0.1713$

When $n=3=\frac{1}{2 ! 2^{3-2}}(0.7931)(0.4321)=0.0857$

When $n=4=\frac{1}{2 ! 2^{4-2}}(0.7931)(0.4321)=0.0428$

When $n=5=\frac{1}{2 ! 2^{5-2}}(0.7931)(0.4321)=0.0214$

When $n=6=\frac{1}{2 ! 2^{6-2}}(0.7931)(0.4321)=0.0107$

When $n=7=\frac{1}{2 ! 2^{7-2}}(0.7931)(0.4321)=0.054$ 


$$
\begin{aligned}
& \text { When } n=8=\frac{1}{2 ! 2^{8-2}}(0.7931)(0.4321)=0.0027 \\
& \text { When } n=9=\frac{1}{2 ! 2^{9-2}}(0.7931)(0.4321)=0.0013 \\
& \text { When } n=10=\frac{1}{2 ! 2^{11-2}}(0.7931)(0.4321)=0.0007 \\
& \text { When } n=11=\frac{1}{2 ! 2^{11-2}}(0.7931)(0.4321)=0.0003 \\
& \text { When } n=12=\frac{1}{2 ! 2^{12-2}}(0.7931)(0.4321)=0.0002 \\
& \text { When } n=13=\frac{1}{2 ! 2^{13-2}}(0.7931)(0.4321)=0.0001
\end{aligned}
$$

Considering Monday traffic, the results in Table 1 indicate that the probability of customers in the queue decreases with increasing number of customers. Furthermore, whilst the probabilities of having 1, 3, 5 and 10 customer (s), for example, in the queue are $0.3427,0.0857,0.0214$ and 0.0007 respectively, that of thirteen is 0.0001 . These findings provide sufficient evidences to argue that it is uncommon to have more than 13 customers in the queue if two of the servers (ATM) are working, ceteris paribus.

\subsection{Analysis of the Parameters of the Queuing Model for the Tuesday Congestion}

Number of servers $=3$

Mean customers arrival rate, $\lambda=32$ per hour.

Mean service rate, $\mu=35$ per hour

Utilization factor, $P=\frac{\lambda}{\mu}=\frac{32}{2 * 35}=0.4571$

Probability of having zero customers in the system

$$
P_{0}=\frac{1}{\left[\sum_{n=0}^{s-1} \frac{(\lambda / \mu)^{n}}{n !}+\frac{(\lambda / \mu)^{s}}{s !} \cdot \frac{1}{1-\lambda /(s \mu)}\right]}
$$

$$
P_{0}=\frac{1}{\left[\frac{(32 / 35)^{0}}{0 !}+\frac{(32 / 35)^{1}}{1 !}+\frac{(32 / 35)^{2}}{2 !}+\frac{(32 / 35)^{3}}{3 !} * \frac{1}{1-\frac{32}{(2 * 35)}}\right]}
$$$$
P_{0}=1+0.9143+0.4180+0.1274+1.8421=2.5670
$$

$$
P_{0}=\frac{1}{2.5670}=0.3896
$$

Average number of customers in the system,

$$
L_{s}=L_{q}+\frac{\lambda}{\mu}=0.0770+\frac{32}{35}=0.9913
$$

Average number of students in the queue

$$
L_{q}=\frac{P_{0}(\lambda / \mu)^{s} P}{s !(1-p)^{2}}=\frac{0.3896\left(\frac{32}{35}\right)^{2}(0.4571)}{3 !(1-0.4571)^{2}}=0.0770
$$

Average time spent in the queue, $W_{q}=\frac{L_{q}}{\lambda}=\frac{0.0770}{32}=$ 0.0024

Average time spent in the system, $W_{s}=W_{q}+\frac{1}{\lambda}=$ $0.0024+\frac{1}{35}=0.0310$

The probability of having $\mathrm{n}$ customers in the system:

Since when $n=0, P_{0}=0.3896$

When $n=1=\frac{1}{1}\left(\frac{32}{35}\right) 0.3896=0.3562$

$$
\begin{aligned}
& \text { When } n=2=\frac{1}{2}\left(\frac{32}{35}\right) 0.3896=0.1781 \\
& \text { When } n=3=\frac{1}{3}\left(\frac{32}{35}\right) 0.3896=0.1187 \\
& \text { When } n=4=\frac{1}{3 ! 2^{4-1}}(0.9143)(0.3896)=0.0022 \\
& \text { When } n=5=\frac{1}{3 ! 2^{5-1}}(0.9143)(0.3896)=0.0007 \\
& \text { When } n=6=\frac{1}{3 ! 2^{6-1}}(0.9143)(0.3896)=0.0002 \\
& \text { When } n=7=\frac{1}{3 ! 2^{7-1}}(0.9143)(0.3896)=0.0000
\end{aligned}
$$

Similarly, x-raying Tuesday traffic in Table 1 , it is evident that the probability of customers in the queue decreases with increasing number of customers. For instance, the computations show that while the probability of having one, three and four customer ( $\mathrm{s}$ ) in the queue is $0.3562,0.1187$ and 0.0022 respectively, the chances of having six customers is 0.0007 . Like the Monday traffic, the results for the Tuesday congestion signify that it is very uncommon to have more than 6 customers in the queue under normal circumstances if the three ATMs are effective.

\subsection{Analysis of the Parameters of the Queuing Model for the Wednesday Congestion}

Number of server $=1$

Mean customers arrival rate, $\lambda=27$ per hour.

Mean service rate, $\mu=32$ per hour

Utilization factor, $P=\frac{\lambda}{\mu}=\frac{27}{2 * 32}=0.8438$ hours

Probability of having zero customers in the system

$$
P_{0}=1-P=1-08438=0.1562
$$

Average number of customers in the system,

$$
L_{s}=\frac{\lambda}{\mu-\lambda}=\frac{27}{32-27}=5.4 \text { customers }
$$

Average number of customers in the queue,

$$
L_{q}=L_{s}-\frac{\lambda}{\mu}=5.4-\frac{27}{32}=4.5563 \text { customers }
$$

Average time spent in the system, $W_{s}=\frac{1}{\mu-\lambda}=\frac{1}{32-27}=\frac{1}{5}=$ 0.2 hours

Average time spent in the queue, $W_{q}=\frac{P}{\mu-\lambda}=\frac{0.8438}{32-27}=$ 0.1688 hours

The probability of having $\mathrm{n}$ customers, $P_{n}=P_{0} P^{n}=(1-$ P) $P^{n}$

When $n=0, P_{0}=1-P=0.1562$

Since $P=0.8438$, then,

When $n=1, P_{1}=0.1562(0.8438)^{1}=0.3427$

When $n=2, P_{2}=0.1562(0.8438)^{2}=0.1112$

When $n=3, P_{3}=0.1562(0.8438)^{3}=0.0938$

When $n=4, P_{4}=0.1562(0.8438)^{4}=0.0792$

When $n=5, P_{5}=0.1562(0.8438)^{5}=0.0668$

When $n=6, P_{6}=0.1562(0.8438)^{6}=0.0564$

When $n=7, P_{7}=0.1562(0.8438)^{7}=0.0476$

When $n=8, P_{8}=0.1562(0.8438)^{8}=0.0401$

When $n=9, P_{9}=0.1562(0.8438)^{9}=0.0339$

When $n=10, P_{10}=0.1562(0.8438)^{10}=0.0286$

When $n=11, P_{11}=0.1562(0.8438)^{11}=0.0241$ 


$$
\begin{aligned}
& \text { When } n=12, P_{12}=0.1562(0.8438)^{12}=0.0203 \\
& \text { When } n=13, P_{13}=0.1562(0.8438)^{13}=0.0172 \\
& \text { When } n=14, P_{14}=0.1562(0.8438)^{14}=0.0145 \\
& \text { When } n=15, P_{15}=0.1562(0.8438)^{15}=0.0122 \\
& \text { When } n=16, P_{16}=0.1562(0.8438)^{16}=0.0103 \\
& \text { When } n=17, P_{17}=0.1562(0.8438)^{17}=0.0087 \\
& \text { When } n=18, P_{18}=0.1562(0.8438)^{18}=0.0073 \\
& \text { When } n=19, P_{19}=0.1562(0.8438)^{19}=0.0062 \\
& \text { When } n=20, P_{20}=0.1562(0.8438)^{20}=0.0052 \\
& \text { When } n=21, P_{21}=0.1562(0.8438)^{21}=0.0044 \\
& \text { When } n=22, P_{22}=0.1562(0.8438)^{22}=0.0037 \\
& \text { When } n=23, P_{23}=0.1562(0.8438)^{23}=0.0031 \\
& \text { When } n=24, P_{24}=0.1562(0.8438)^{24}=0.0027 \\
& \text { When } n=25, P_{25}=0.1562(0.8438)^{25}=0.0022 \\
& \text { When } n=26, P_{26}=0.1562(0.8438)^{26}=0.0019 \\
& \text { When } n=27, P_{27}=0.1562(0.8438)^{27}=0.0016
\end{aligned}
$$

From Table 1 , it is pragmatic that on Wednesdays, the characteristics of the queuing system are quite similar with those of Mondays and Tuesdays as evident in the probability values. For instance, whereas the probabilities of having 7,8 , 9 and 10 customers in the queue are $0.0476,0.0401,0.0339$ and 0.0286 respectively, their cumulative probabilities are respectively $0.7430,0.7831,0.8170$ and 0.8456 signifying that as the number of customers in the queue increases, its probability approaches zero, the cumulative probabilities are fast approaching 1 and vice-versa. The implication of this finding is that, under normal conditions, the chances of having 27 customers in the queue are very slim.

The parameter for two servers was solved previously. The parameter for the three servers is as follows:

Number of servers $=3$

Mean customers arrival rate, $\lambda=23$ per hour.
Mean service rate, $\mu=29$ per hour

\begin{tabular}{|c|c|c|c|c|c|c|c|c|}
\hline \multirow{3}{*}{$\mathbf{N}$} & \multirow{3}{*}{$\begin{array}{l}\text { Monday } \\
m / m / 2: F C F S \\
\mathrm{P}\end{array}$} & \multirow{3}{*}{$\begin{array}{l}\text { Tuesday } \\
m / m / 3: F C F S \\
\mathrm{P}\end{array}$} & \multirow{3}{*}{$\begin{array}{l}\text { Wednesday } \\
m / m / 1: F C F S \\
\mathrm{P}\end{array}$} & \multirow{3}{*}{ C.P } & \multirow{2}{*}{\multicolumn{4}{|c|}{ Comparison of the Models }} \\
\hline & & & & & & & & \\
\hline & & & & & Par & $m / m / 1$ & $m / m / 2$ & $m / m / 3$ \\
\hline 0 & 0.4321 & 0.3896 & 0.1562 & 0.1562 & $\Lambda$ & 27 & 23 & 23 \\
\hline 1 & 0.3427 & 0.3562 & 0.1318 & 0.2880 & M & 32 & 29 & 29 \\
\hline 2 & 0.1713 & 0.1781 & 0.1112 & 0.3992 & $P$ & 0.8438 & 0.3966 & 0.2644 \\
\hline 3 & 0.0857 & 0.1187 & 0.0938 & 0.4930 & $\mathrm{P}(0)$ & 0.1562 & 0.4321 & 0.4503 \\
\hline 4 & 0.0428 & 0.0022 & 0.0792 & 0.5722 & $L_{s}$ & 5.4 & 0.9411 & 0.8114 \\
\hline 5 & 0.0214 & 0.0007 & 0.0668 & 0.0668 & $L_{q}$ & 4.5563 & 0.148 & 0.0183 \\
\hline 6 & 0.0107 & 0.0002 & 0.0564 & 0.6954 & $W_{s}$ & 0.2 & 0.0409 & 0.0035 \\
\hline 7 & 0.0054 & & 0.0476 & 0.7430 & $W_{q}$ & 0.1688 & 0.0064 & 0.0008 \\
\hline 8 & 0.0027 & & 0.0401 & 0.7831 & & & & \\
\hline 9 & 0.0013 & & 0.0339 & 0.8170 & & & & \\
\hline 10 & 0.0007 & & 0.0286 & 0.8456 & & & & \\
\hline 11 & 0.0003 & & 0.0241 & 0.8697 & & & & \\
\hline 12 & 0.0002 & & 0.0203 & 0.8900 & & & & \\
\hline 13 & 0.0001 & & 0.0172 & 0.9072 & & & & \\
\hline 14 & & & 0.0145 & 0.9217 & & & & \\
\hline 15 & & & 0.0122 & 0.9339 & & & & \\
\hline 16 & & & 0.0103 & 0.9442 & & & & \\
\hline 17 & & & 0.0087 & 0.9529 & & & & \\
\hline 18 & & & 0.0073 & 0.9602 & & & & \\
\hline 19 & & & 0.0062 & 0.9664 & & & & \\
\hline 20 & & & 0.0052 & 0.9716 & & & & \\
\hline 21 & & & 0.0044 & 0.9760 & & & & \\
\hline 22 & & & 0.0037 & 0.9797 & & & & \\
\hline 23 & & & 0.0031 & 0.9828 & & & & \\
\hline
\end{tabular}

Utilization factor, $P=\frac{\lambda}{s \mu}=\frac{23}{3 * 29}=0.2644$

Probability of having zero customers in the system

$$
P_{0}=\frac{1}{\left[\sum_{n=0}^{s-1} \frac{(\lambda / \mu)^{n}}{n !}+\frac{(\lambda / \mu)^{s}}{s !} \cdot \frac{1}{1-\lambda /(s \mu)}\right]}
$$

$$
P_{0}=\frac{1}{\left[\frac{(23 / 29)^{0}}{0 !}+\frac{(23 / 29)^{1}}{1 !}+\frac{(23 / 29)^{2}}{2 !}+\frac{(23 / 29)^{3}}{3 !} * \frac{1}{1-\frac{23}{(2 * 29)}}\right]}
$$

$P_{0}=1+0.7931+0.3145+0.0831 * 1.8421=2.2206$

$$
P_{0}=\frac{1}{2.2206}=0.4503
$$

Average number of customers in the system,

$$
L_{s}=L_{q}+\frac{\lambda}{\mu}=0.0183+\frac{23}{29}=0.8114
$$

Average number of students in the queue

$$
L_{q}=\frac{P_{0}(\lambda / \mu)^{s} P}{s !(1-p)^{2}}=\frac{0.4503\left(\frac{23}{29}\right)^{3}(0.4571)}{3 !(1-0.4571)^{2}}=0.0183
$$

Average time spent in the queue, $W_{q}=\frac{L_{q}}{\lambda}=\frac{0.0183}{23}=$ 0.0008

Average time spent in the system, $W_{s}=W_{q}+\frac{1}{\lambda}=$ $0.0008+\frac{1}{29}=0.0035$

Table 1. Empirical Results of the Models for the Monday-Wednesday Congestions. 


\begin{tabular}{|c|c|c|c|c|c|c|c|c|}
\hline \multirow[t]{2}{*}{$\mathbf{N}$} & \multirow{2}{*}{$\begin{array}{l}\text { Monday } \\
m / m / 2: F C F S \\
\mathrm{P}\end{array}$} & \multirow{2}{*}{$\begin{array}{l}\text { Tuesday } \\
m / m / 3: F C F S \\
\mathrm{P}\end{array}$} & \multirow{2}{*}{$\begin{array}{l}\text { Wednesday } \\
m / m / 1: F C F S \\
\mathrm{P} \\
\end{array}$} & \multirow{2}{*}{ C.P } & \multicolumn{4}{|c|}{ Comparison of the Models } \\
\hline & & & & & Par & $m / m / 1$ & $m / m / 2$ & $m / m / 3$ \\
\hline 24 & & & 0.0027 & 0.9855 & & & & \\
\hline 25 & & & 0.0022 & 0.9877 & & & & \\
\hline 26 & & & 0.0019 & 0.9896 & & & & \\
\hline 27 & & & 0.0016 & 0.9912 & & & & \\
\hline
\end{tabular}

From Table 1, the results also show the efficiency parameters under different queuing models. The traffic intensity has changed significantly from $84.38 \%$ to $39.66 \%$ and to $26.44 \%$. This shows that as more servers (ATM) are introduced, then the banking premises become less busy which have the potential of attracting more patronage.

\section{Conclusion and Policy Implications}

\subsection{Conclusion}

The study examined queuing characteristics at the Kaura Namoda branch of First Bank Nigeria Ltd. Waiting line data were collected from Monday to Wednesday through observation. The study analyzed queuing efficiency parameters under the one-server, two-server and three-server models. The average number of customers in the queue was found to be $0.1480,0.0770$ and 4.5563 on Mondays, Tuesdays and Wednesdays, implying that $39.66 \%, 45.71 \%$ and $84.38 \%$ of arriving customers per hour have to wait to be served on those days respectively. Furthermore, customers' waiting and service times in the system are, on average, 0.2 hours (12 minutes), 0.0469 hours (about 3 minutes) and 0.031 hours (about 2 minutes) when the server is one, two or three respectively. In the main, the pattern of operations implies that traffic intensity is model dependent suggesting that higher number of servers is associated with higher service efficiency and vice-versa. Thus, the study argues for the three-server model against the one or two-server model.

\subsection{Policy Implications}

The results provide evidence to suggest that in order to continue to serve its teeming customers optimally, the management of the bank should maintain three servers (ATMs). The findings also suggest the need for proportionate increase in the number of ATMs as the number of users increases. Furthermore, the need to introduce servers that are capable of accepting deposits in addition to dispensing cash is also advocated as this will further minimize waiting and service time and attract potential customers to the bank. Finally, the study recommends steady power supply by way of alternative sources in order to achieve smooth operations.

\section{References}

[1] Sheikh, T., S. K. Singh, and A. K. Kashyap, (2013). A Study of Queuing Model for Banking System. International Journal of Industrial Engineering and Technology, 5 (1), 21-26.

[2] Cabas, M. G. (2001). A History of the Future of Banking:
Predictions and Outcomes. Available at http://www.hass.berkley.edu/finance/CMWpaper.pdf.

[3] Moulinho, L. (1992). Customer Satisfaction Measurements: Prolonged Satisfaction with ATMs. International Journal of Bank Marketing, 10 (7), 30-37.

[4] Okechi, O., and O. M. Kepeghorn (2013). Empirical Evaluation of Customers' Use of Electronic Banking System in Nigeria. African Journal of Computing and ICT, 6 (1), 7-20.

[5] Erlang, A. K. (1909). The Theory of Probabilities and Telephone Conversations (Nyttidsskrift for Mathematics), B, 20, p. 33.

[6] Nita, H. S., M. G. Ravi, and S. Hardik (2010). Operations Research. 4th Edition, ISBN 978-81- 203-3128-0. Eastern Economy Edition.

[7] Tiwari N. K., and S. K. Shandilya (2009). Operations Research. Third Edition, ISBN 978-81-203- 2966-9. Eastern Economy Edition.

[8] Augustine, A. N. (2013). Queuing Model as a Technique of Queue Solution in Nigeria Banking Industry. Developing Countries Studies, 3 (8), 188-195.

[9] Eze, E. O., and A. D. Odunukwe (2015). On Application of Queuing Models to Customers Management in Banking System. American Research Journal of Bio Sciences, 1 (2), 14-20.

[10] Agyei, W., C. Asare-Darko, and F. Odilon (2015). Modeling and Analysis of Queuing Systems in Banks: (A case study of Ghana Commercial Bank Ltd. Kumasi Main Branch). International Journal of Scientific \& Technology Research, 4 (7), 160-163.

[11] Abiodun, R. O., and N. I. Omosule (2015). Queuing Model for Banking System: A Comparative Study of Selected Banks in Owo Local Government Area of Ondo State, Nigeria. American Journal of Engineering Research (AJER), 4 (8), 191-195.

[12] Zewude, B. T. (2016). Queuing Modeling for Comparative Study of Banking System on Commercial Bank of Ethiopia Tona Branch and Dashen Bank: The Case of Wolaita Zone, Ethiopia. Research Journal of Finance and Accounting, 7 (21), 11-16.

[13] Jhala, N., and P. Bhathawala (2016). Application of Queuing Theory in Banking Sector. IOSR Journal of Mathematics (IOSR-JM), 12 (2 Ver. II), 73-75.

[14] Kabamba, A. M. (2019). Modeling and Analysis of Queuing Systems in Banks: A Case Study of Banque Commerciale duCongo-BCDC/Mbujimayi. Available at https://mpra.ub.unimuenchen.de/92579/MPRA Paper No. 92579.

[15] Kendall, D. G. (1953). Stochastic Processes Occurring in the Theory of Queues and their Analysis by the Method of the Imbedded Markov Chain. The Annals of Mathematical Statistics, 24 (3), 388.

[16] Lee, A. M. (1966). Applied Queuing Theory, St. Martins Press. New York, 1966. 